\title{
Screening of highly efficient photosynthetic hybrids of Oryza officinalis and analysis of their photosynthetic pathway genes
}

\author{
E.X. LI", F.Y. YIN", C. LI"**, D.Y. KAN", J.H. YOU ${ }^{* * *}$, S.Q. XIAO*, Z.Q. CHENG ${ }^{*}$, and X. KE ${ }^{*,+}$ \\ Biotechnology and Germplasm Resources Institute, Yunnan Academy of Agricultural Sciences, 650205 Kunming, \\ China* \\ Zhaotong University, 657000 Zhaotong, China** \\ Technology Center of China Tobacco Yunnan Industrial Co., 650023 Kunming, China ${ }^{* * *}$
}

\begin{abstract}
Hereditary properties of strong growth and huge accumulation of biomass in Oryza officinalis exhibit a great potential; however, the genes that code for its high photosynthesis performance are not established. This study screened eight hybrids, using biomass accumulation and photosynthesis analysis, based on the introgression lines constructed by analyzing distant hybridization patterns between Oryza officinalis and cultivars HY-8. We designed 23 primer pairs using transcriptome sequencing of Oryza officinalis and screened two types of photosynthetic enzymes: phosphoenolpyruvate carboxylase (PEPC) and pyruvate orthophosphate dikinase (PPDK), which are two related proteins of ribulose-1,5-biphosphate carboxylase/oxygenase (Rubisco), its binding protein (rubis-subs-bind), and a small subunit (rbcS). Results showed that $\mathrm{C}_{4}$ photosynthetic pathway enzymes, PEPC and PPDK, were highly expressed in hybrids and the source plant, Oryza officinalis. Homology analysis also indicated that the sequences of those two genes were different from those of the $\mathrm{C}_{3}$ and $\mathrm{C}_{4}$ plants investigated. Therefore, a better understanding of the photosynthetic characteristics of Oryza officinalis would provide clues for further isolation of valuable genes from this plant.
\end{abstract}

Keywords: excellent traits; gene homology; PCR amplification; photosynthetic parameters; primer design.

\section{Introduction}

As the population grows exponentially and the continuous decrease in arable land becomes evident, rice yield increases per unit become significant and necessary
(Murchie et al. 2009). However, these issues become increasingly challenging under existing conditions, such as the type of plant, the density of planting, pest control, and soil status. Thus, one potential way to improve this situation is to enhance photosynthesis (von Caemmerer

\section{Highlights}

- The distant hybridization between Oryza officinalis and cultivars has been achieved.

- Highly efficient photosynthetic traits were certainly identified in hybrids

- Homologous genes of PEPC and PPDK from Oryza officinalis show genetic diversity
Received 19 September 2020

Accepted 6 April 2021

Published online 17 May 2021

Corresponding author

e-mail: kexue7788@163.com

Abbreviations: $\mathrm{Chl}$ - chlorophyll; $C_{\mathrm{i}}-$ intercellular $\mathrm{CO}_{2}$ concentration; $E$ - transpiration rate; $\mathrm{F}_{\mathrm{v}} / \mathrm{F}_{\mathrm{m}}-$ maximum photochemical efficiency of PSII; $g_{s}$ - stomatal conductance; PEPC - phosphoenolpyruvate carboxylase; PPDK - pyruvate orthophosphate dikinase; $P_{\mathrm{N}}$ - net photosynthetic rate; PSII-BNR - photosynthesis system II assembly factor YCF48; rbcL - large subunits of Rubisco; $\mathrm{rbcS}$ - small subunits of Rubisco; Rubisco - ribulose-1,5-biphosphate carboxylase/oxygenase; rubis-subs-bind - Rubisco large subunit methyltransferase substrate binding domain; SPAD - Soil and Plant Analyzer Development for chlorophyll content SPAD reading. Acknowledgments: The Applied Basic Research Foundation of Yunnan Province (2018FB035, 2018ZG005, 2018FG001-068) and National Natural Science Fund of China (31460054) supported this study.

Conflict of interest: The authors declare that they have no conflict of interest. 
et al. 2012, Zhang et al. 2019). Research indicates rice photosynthetic efficiency could improve significantly by transferring one or more photosynthesis enhancement enzyme genes from other $\mathrm{C}_{4}$ crops, such as corn, sorghum, barnyard grass, and millet, to $\mathrm{C}_{3}$ rice crops (Zhang et al. 2003, Wang et al. 2016). These enzymes, such as Rubisco activase (Rca), phosphoenolpyruvate carboxylase (PEPC) (Deng et al. 2016), and pyruvate orthophosphate dikinase (PPDK), increased the yield by 10-20\% (Gu et al. 2013, Wang et al. 2015, Sen et al. 2017) in $\mathrm{C}_{4}$ crops. This increase presents advantages of photosynthetic efficiency, productivity, water efficiency, and strong tolerance to hot weather and drought (Ding et al. 2013, El-Sharkawy 2016).

Similarly, further research on transgenic rice with these $\mathrm{C}_{4}$ photosynthetic enzymes revealed that increased PEPC activity in transgenic rice could alleviate the decrease in photosynthesis and yield under drought conditions (Ding et al. 2015). The $\mathrm{C}_{4}$ genes improved drought tolerance by stabilizing thylakoid membrane function and structure (Shen et al. 2015). Therefore, the construction of $\mathrm{C}_{4}$ rice has become a research hotspot of rice photosynthesis (von Caemmerer et al. 2012). There is a potential risk of transgene since the genes derived from these nonrice plants have a great difference compared to cultivars. Expression of these genes may be a problem because their regulatory elements do not match Oryza sativa, thus further affecting a crop function. This process still serves as a viable option to increase rice yield (Suzuki et al. 2007). Oryza sativa from the wild rice ancestor derives its genetic basis from these ancestors, on which Oryza sativa varieties could be greatly expanded (Yang et al. 2005). Among them, the Oryza officinalis variant exists, which exhibits hereditary properties of strong growth, huge accumulation of biomass, and developed vascular bundles, as well as certain similarities with $\mathrm{C}_{4}$ plants, such as stress resistance, high yield, and photosynthetic efficiency. Previous experiments have shown the photosynthetic efficency of Oryza officinalis to be the highest among several wild rice sources (Kiran et al. 2013). In this study, Oryza officinalis presented more than 20 times higher amount of biomass accumulation than Oryza sativa, and carboxylation efficiency and light-aturation point were more than twice that of ordinary cultivars. However, its high photosynthetic efficiency mechanism is unclear, especially the genes that code for its high photosynthetic efficiency traits, whether they are $\mathrm{C}_{3}$ or $\mathrm{C}_{4}$ pathway photosynthetic enzyme genes or other unknown genes (Duan et al. 2008, Zhang et al. 2019). It is thus important to validate which genes code for these exceptional traits. Studies have shown that $\mathrm{C}_{3}$ plants contain at least two sets of varying photosynthetic enzyme genes. One set encodes enzymes with housekeeping functions and the other is very similar to $\mathrm{C}_{4}$ photosynthetic enzymes in $\mathrm{C}_{4}$ plants but with low expression (Shen et al. 2016).

Therefore, to study the photosynthetic basis for the strong growth and huge accumulation of biomass possessed by Oryza officinalis, transcriptome analysis of Oryza officinalis to screen genes related to photosynthetic pathways was applied. In contrast, the gene identification of the progeny materials constructed by the wild cross was conducted (Deng et al. 2004), thus establishing the foundation for evaluating and understanding the high photosynthetic efficiency potential of Oryza officinalis.

\section{Materials and methods}

Experimental materials: Oryza officinalis, the Yunnan Gengma type, was chosen as the male parent, while HY-8, a cultivar with red seeds, high-quality, and strong disease resistance, was chosen as the female parent. $F_{1}$ was obtained of this cross; the progeny materials $\mathrm{BC}_{1} \mathrm{~F}_{1}$ and $\mathrm{BC}_{2} \mathrm{~F}_{1}$ were obtained by successive backcrossing with $\mathrm{F}_{1}$ and $\mathrm{BC}_{1} \mathrm{~F}_{1}$ as the female parent and HY-8 as the male parent. All materials were planted in the experimental base of the Yuanjiang County, Yunnan, China.

Photosynthesis-related indexes and biomass: Photosynthetic parameters were determined based on the method of $\mathrm{Ye}$ and $\mathrm{Yu}$ (2008). The flag leaves with similar colors and no curling or pests were selected at the booting stage. After that, we measured the photosynthesis parameters, such as $P_{\mathrm{N}}$, stomatal conductance $\left(g_{\mathrm{s}}\right)$, intercellular $\mathrm{CO}_{2}$ concentration $\left(C_{\mathrm{i}}\right)$, and transpiration rate $(E)$ using a $L i-6400 X T$ photosynthesis analyzer ( $\mathrm{Li}-\mathrm{COR}$, USA). The measuring conditions were as follows: leaf chamber temperature was $25^{\circ} \mathrm{C}$, the light was $1,200 \mu \mathrm{mol}$ (photon) $\mathrm{m}^{-2} \mathrm{~s}^{-1}$, and the concentration of $\mathrm{CO}_{2}$ was $400 \mu \mathrm{mol} \mathrm{mol}^{-1}$. Measurements were done in triplicates, after which an average value was obtained.

Also, based on the method of Yang and Qiao (2009), we determined the chlorophyll (Chl) content (SPAD). We used the SPAD-502 chlorophyll (Chl) analyzer (Japan) to obtain the flag leaf and the second leaf SPAD values. Counting from the top, we chose three different parts of each leaf for measurement and obtained the average value.

The biomass accumulation was then calculated based on the dry mass of a single stem. For biomass determination, we harvested aerial parts. The number of tillers was counted at the end of the Oryza growth period, after which a green-killing treatment was performed at $105^{\circ} \mathrm{C}$ for $30 \mathrm{~min}$, then dried at $80^{\circ} \mathrm{C}$ for $12 \mathrm{~h}$, and weighed.

Primer design and screening: We screened six unique genes related to photosynthesis in Oryza officinalis, which are genes of rubis-subs-bind, $\mathrm{rbcS}$, rbcL (large subunit of Rubisco), PSII-BNR (photosynthesis system II assembly factor YCF48), PPDK, and PEPC based on the sequencing results from the Oryza officinalis transcriptome. Methods in literature were used to design primers based on geneconserved regions using Primer Premier 5.0 software, while evaluation was achieved using Oligo 6.0, resulting in 88 pairs of primers. The Shuoqing Biotechnology Company also accomplished synthesis. The total volume of the PCR reaction system was $10 \mu \mathrm{L}$, including $1 \mu \mathrm{L}$ for template DNA $(100 \mathrm{ng}) ; 1 \mu \mathrm{L}$ of $10 \mu \mathrm{mol} \mathrm{L}^{-1}$ for upstream and downstream primers, respectively; $5 \mu \mathrm{L}$ for the Taq PCR MasterMix, and $2 \mu \mathrm{L}$ of $\mathrm{ddH}_{2} \mathrm{O}$. The following PCR program was used: $94^{\circ} \mathrm{C}$ for $3 \mathrm{~min} ; 94^{\circ} \mathrm{C}$ for $30 \mathrm{~s}, 55-$ $62^{\circ} \mathrm{C}$ for $30 \mathrm{~s}, 72^{\circ} \mathrm{C}$ for $30 \mathrm{~s}$, for $35-40$ cycles; $72^{\circ} \mathrm{C}$ for 
5 min. After verification by PCR amplification, 23 primer pairs that could amplify the unique sequence of Oryza officinalis were selected.

Screening of photosynthetic genes: We extracted genomic DNA from Oryza officinalis, HY-8, and the hybrid progeny. Also, the 23 pairs of specifically designed primers were used for gene screening the hybrid progeny materials, Oryza officinalis, and HY-8. We purchased DNA extraction and PCR reaction kits from Beijing Tiangen Biological Company. The sequence was also obtained through the sequencing of these PCR products by Shuoqing Biotechnology Company.

Detection of photosynthetic gene expression: Primer Premier v. 5.0 was used to design the primers (Table 1S, supplement) after Shuoqing Biotechnology Company had accomplished synthesis. Total plant RNA was extracted from Oryza officinalis, cultivars HY-8, and 20 hybrids using flag leaves and second leaves, which were at the booting stage, while the extraction kit was Promega from Beijing Biotechnology Company, and PrimeScript $1{ }^{\text {st }}$ Strand cDNA Synthesis Kit was from TaKaRa Bio Company. qRT-PCR was performed on the QuantStudio $12 \mathrm{~K}$ Flex real-time quantitative PCR system in triplicates. We compared the relative expression levels of photosynthetic genes in various materials from Oryza officinalis.

Gene homology analysis: We obtained the coding sequences (CDS) of the complete gene and its corresponding typical $\mathrm{C}_{3}$ and $\mathrm{C}_{4}$ PEPC and PPDK plant amino acid sequences from the National Center for Biotechnology Information. After that, we analyzed the gene homology using Maga-X and compared it with CDS sequences and the corresponding amino acid sequences, amplified from Oryza officinalis.

\section{Results}

Selection of high-light-efficiency lines in hybrid progeny materials: We obtained hybrid $\mathrm{F}_{1}$ generation materials of Oryza officinalis and cultivar HY-8 through remote hybridization combined with embryo rescue and backcross progeny materials of different generations (Fig. 1S, supplement). For now, the highest generation was $\mathrm{BC}_{4} \mathrm{~F}_{1}$. We tested these progeny materials for hybrid identification of the F1 generation by employing 50 standard simple sequence repeats (SSR) markers (http://gramene.org/). Among the 50 SSR markers, 33 were amplified, while 10 were polymorphic. As a result, F1 plants were hybrids of HY-8 and O. officinalis (Fig. 2S, supplement). Hybrids also showed many excellent agronomic traits, such as long panicle, longer and wider leaves, compact plant shape, and bacterial blight resistance. The maximum panicle length, leaf length, and leaf width of $\mathrm{BC}_{1} \mathrm{~F}_{1}$ were $44.5,78$, and $3.5 \mathrm{~cm}$, respectively (Table 1 ). Due to the limited number of materials, only $\mathrm{F}_{1}, \mathrm{BC}_{1} \mathrm{~F}_{1}$, and $\mathrm{BC}_{2} \mathrm{~F}_{1}$ were used in this experiment. Also, characteristics of the parent Oryza officinalis were revealed in part of the hybrid offspring's vigorous growth. Thus, to select high-efficiency hybrid offspring from them, biomass accumulation and photosynthetic rates were measured (Table 2).

The biomass accumulation measurements revealed a significant difference in biomass accumulation between materials. The main stem dry mass without the root was taken as an indicator of the amount of biomass accumulation. The average value of all materials was $5.32 \mathrm{~g}$. The smallest one was $2.56 \mathrm{~g}$, and the largest one was $9.93 \mathrm{~g}$, where the biomass accumulation of Oryza officinalis and HY-8 was only $5.47 \mathrm{~g}$ and $3.21 \mathrm{~g}$, respectively. There were ten super-parents accumulating biomass in the offspring of the tested hybrids as well, i.e., FC7-21, FC7-18, FC7-8, FC7-10, FC7-4, F1-3-7, FC7-9, FC7-17, $\mathrm{F}_{1}-1-3$, and $\mathrm{FC} 7-2$.

Parameters related to photosynthesis also revealed that SPAD, $E, C_{\mathrm{i}}$, and $P_{\mathrm{N}}$ were significantly different between the plants, except $g_{\mathrm{s}}$. The average $P_{\mathrm{N}}$ of all materials was 11.1 $\mu \mathrm{mol}\left(\mathrm{CO}_{2}\right) \mathrm{m}^{-2} \mathrm{~s}^{-1}$, which was equivalent to that of Oryza officinalis with $11.2 \mu \mathrm{mol} \mathrm{m} \mathrm{m}^{-2} \mathrm{~s}^{-1}$, while HY-8 was $8.9 \mu \mathrm{mol} \mathrm{m} \mathrm{m}^{-2} \mathrm{~s}^{-1}$. In comparison, the highest one was found in a hybrid progeny FC7-21 with $18.2 \mu \mathrm{mol} \mathrm{m}^{-2} \mathrm{~s}^{-1}$, which was 1.6 times higher than that of the Oryza officinalis parent and twice that of HY-8. Minimum $P_{\mathrm{N}}$ was $5.2 \mu \mathrm{mol}$ $\mathrm{m}^{-2} \mathrm{~s}^{-1}$. The average value of $g_{\mathrm{s}}$ was $0.23 \mathrm{~mol} \mathrm{~m}^{-2} \mathrm{~s}^{-1}$. The $g_{\mathrm{s}}$ of Oryza officinalis $\left(0.22 \mathrm{~mol} \mathrm{~m}^{-2} \mathrm{~s}^{-1}\right)$ was slightly higher than that of HY-8 $\left(0.16 \mathrm{~mol} \mathrm{~m}^{-2} \mathrm{~s}^{-1}\right)$, but there was no significant difference. The SPAD value was 48 on average, with the highest of the hybrid progeny material being 53 , the lowest being 42 , and the difference between parents being 47 . The average $E$ and $C_{\text {i }}$ were $2.7 \mathrm{mmol}\left(\mathrm{H}_{2} \mathrm{O}\right) \mathrm{m}^{-2} \mathrm{~s}^{-1}$ and $222 \mu \mathrm{mol}\left(\mathrm{CO}_{2}\right) \mathrm{mol}^{-1}$, respectively, and both $E$ and $C_{\mathrm{i}}$ were equivalent to the parents. According to a comprehensive analysis of five indicators related to photosynthesis, 14 hybrid progeny materials, which had photosynthesis higher than that of the HY-8 parent, were selected, i.e., FC7-21, FC7-18, FC7-8, F 1 -2-5, FC7-10, F1-3-4, FC7-4, FC7-22, F 1 -3-7, F F-3-9, FC7-25, FC7-19, FC7-9, and FC7-17.

The biomass accumulation was related to photosynthesis. Theoretically, the stronger the photosynthesis, the stronger the carbon assimilation, and thus, the higher biomass accumulation. Due to the introduction of excellent genetic traits of Oryza officinalis, hybrid progeny materials created by Oryza officinalis and the cultivar HY-8 demonstrated super-parent advantages. Eight of these hybrids demonstrated characteristics of a huge biomass accumulation and strong photosynthetic efficiencies, i.e., FC7-21, FC7-18, FC7-8, FC7-10, FC7-4, F 1 -3-7, FC7-9, and FC7-17. The excellent genes were thus worthy of further exploring these materials.

Screening of specific primers for the photosynthetic gene detection: First, we screened specific primers to identify the photosynthetic genes or sequences of Oryza officinalis. We obtained 654,243 unique annotation sequences of Oryza officinalis by the Hidden Markov model using the HMMSCAN program and obtained six types of photosynthesis-related gene sequences, including 58 gene sequences for Rubisco-binding protein, 21 gene sequences for Rubisco small subunit (rbcS), 8 gene sequences 
Table 1. Some agronomic traits of $\mathrm{F}_{1}$ and $\mathrm{BC}_{1} \mathrm{~F}_{1}$ hybrids. Each value of hybrid progeny is an average of 20 tests, '-' means missing data.

\begin{tabular}{lllll}
\hline Traits & $\mathrm{HY}-8$ & $\mathrm{~F}_{1}$ & $\mathrm{BC}_{1} \mathrm{~F}_{1}$ & Oryza officinalis \\
\hline Plant height [cm] & 82.5 & 168.5 & 113.5 & 210.0 \\
Stem diameter [cm] & 0.6 & 0.5 & - & 0.4 \\
Length of flag leaf [cm] & 28.7 & 24.4 & 31.6 & 16.1 \\
Width of flag leaf [cm] & 2.1 & 2.5 & 2.5 & 1.5 \\
Length of the second leaf [cm] & 44.7 & 45.3 & 58.1 & 36.2 \\
Width of the second leaf [cm] & 1.84 & 2.16 & 2.1 & 1.48 \\
Total tiller & 10 & 76 & - & 122 \\
Tiller of high position node & none & 205 & - & none \\
Panicle length [cm] & 24.76 & 30.94 & 34.9 & 29.76 \\
Total spikelets & 146.6 & 269.6 & 235.6 & 172.8 \\
Filled grain numbers & - & 2.4 & - & - \\
1,000-grain mass [g] & 29.8 & 14.3 & - & 9.2 \\
Primary branch & 11.0 & 12.6 & - & 10.2 \\
Awn length [cm] & 0.40 & 2.96 & - & 0.58 \\
Length of seed [cm] & 0.99 & 0.66 & - & 0.50 \\
Width of seed [cm] & 0.34 & 0.29 & - & 0.28 \\
Neck length [cm] & -13.4 & -2.3 & -14.4 & 33.0 \\
Leaf pubescence & many & many & - & less \\
Internode color & none & none & - & none \\
Panicle type & tight & tight & - & loose \\
Plant shape & compact & compact & - & loose \\
Resistant to Xanthomonas oryzae pv. oryzae & resistant & resistant & - & resistant \\
Stigma color & none & purple & - & purple \\
\hline
\end{tabular}

for Rubisco large subunit (rbcL), 9 gene sequences for photosystem II BNR domain-containing protein (PSIIBNR), 26 gene sequences for pyruvate phosphodikinase (PPDK), and 61 gene sequences for phosphoenolpyruvate carboxylase (PEPC). All these gene sequences were related to $\mathrm{C}_{3}$ and $\mathrm{C}_{4}$ photosynthetic pathways in Oryza officinalis, and among them, PEPC and PPDK are the key enzymes of the $\mathrm{C}_{4}$ pathway.

Based on a comparison of the genes mentioned above, the largest homologous segment of this class sequence was determined, the design of the 88 pairs of primers was achieved, and PCR amplification was conducted between the two parents of the hybrid offspring. To determine the genes involved in the photosynthetic pathway for Oryza officinalis or the genes that were different from those of the other cultivars, we amplified the selected primer in Oryza officinalis but could not detect a target fragment in the HY-8 cultivar. As a result, only 23 pairs of primers were screened from the initial 88 pairs of primers because amplification of the target bands was only possible in Oryza officinalis (Table 3).

$\mathrm{C}_{4}$ photosynthetic genes of PEPC and PPDK were detected by specific primers: In order to screen the source genes of Oryza officinalis, HY-8, Oryza officinalis, and 14 hybrid progeny plants were detected by PCR with 23 pairs of primers. We detected genes of PEPC, rubissubs-bind, rbcS, and PPDK were detected and focused on $\mathrm{C}_{4}$ photosynthetic pathway genes of PEPC and PPDK.
The genes of PEPC were detected in hybrid FC7-18, and FC7-9 by primer PEPC-9, and the same in $\mathrm{F}_{1}-2-5$ and $\mathrm{F}_{1}$-3-9 by primer $P E P C-27$. The genes of Rubisco were also detected by primer Rubis-2.1 in F $\mathrm{F}_{1}-3-4$, FC7-4, and FC7-22. The genes of Rubisco small subunit were also detected by primer $r b c S-3$ in all hybrid progenies except $\mathrm{F}_{1}-3-7$, while the gene of PPDK was detected in all hybrid progenies by primer PPDK-11 (Table 4).

Based on these results, the genes of Rubisco small subunit (rbcS) and PPDK were commonly found in hybrid progenies, while some of the hybrid progenies contained PEPC and Rubisco-binding protein gene fragments. Also, there were 13 pairs of primers in total for two genes of PEPC and PPDK. We detected 12 pairs of primers in the target bands of FC7-18 and 11 pairs in FC7-17. This detection rate was 92 and $85 \%$, respectively; 10 pairs of primers in the target bands of FC7-10 and $\mathrm{F}_{1}-3-7$ with a detection rate of $77 \%$; and FC7-8, FC7-9, and FC7-21 showing a detection rate of $69 \%$. Results are as shown in Table 4.

Results also showed that PEPC and PPDK belonged to enzymes of the $\mathrm{C}_{4}$ photosynthetic pathway and occurred more frequently in eight hybrid progenies with super affinity in biomass accumulation and photosynthesis. Thus, to screen out the unique genes from Oryza officinalis, we discovered that the primers selected for gene detection could not amplify the target bands in the HY-8 cultivar, while PEPC and PPDK, two key photosynthetic enzymes in the $\mathrm{C}_{4}$ photosynthetic pathway, were detected in Oryza 
Table 2. Biomass accumulation and photosynthesis parameters of various rice materials. ' $*$ ' indicates that both biomass and $P_{\mathrm{N}}$ are significantly superior. $C_{\mathrm{i}}$ - intercellular $\mathrm{CO}_{2}$ concentration; $E$ - transpiration rate; $g_{\mathrm{s}}-$ stomatal conductance; $P_{\mathrm{N}}-$ net photosynthetic rate; SPAD - Soil and Plant Analyzer Development for chlorophyll content SPAD reading.

\begin{tabular}{|c|c|c|c|c|c|c|}
\hline Plants & $\begin{array}{l}\text { Dry mass per } \\
\text { tiller }[\mathrm{g}]\end{array}$ & SPAD & $\begin{array}{l}E \\
{\left[\mathrm{mmol}\left(\mathrm{H}_{2} \mathrm{O}\right) \mathrm{m}^{-2} \mathrm{~s}^{-1}\right]}\end{array}$ & $\begin{array}{l}C_{\mathrm{i}} \\
{\left[\mu \mathrm{mol}\left(\mathrm{CO}_{2}\right) \mathrm{mol}^{-1}\right]}\end{array}$ & $\begin{array}{l}g_{\mathrm{s}} \\
{\left[\mathrm{mol}\left(\mathrm{H}_{2} \mathrm{O}\right) \mathrm{m}^{-2} \mathrm{~s}^{-1}\right]}\end{array}$ & $\begin{array}{l}P_{\mathrm{N}} \\
{\left[\mu \mathrm{mol}\left(\mathrm{CO}_{2}\right) \mathrm{m}^{-2} \mathrm{~s}^{-1}\right]}\end{array}$ \\
\hline HY-8 & $3.21 \pm 0.24$ & $47 \pm 1$ & $2.3 \pm 0.2$ & $280 \pm 8$ & $0.16 \pm 0.05$ & $8.9 \pm 0.8$ \\
\hline Oryza officinalis & $5.47 \pm 0.31$ & $47 \pm 1$ & $2.8 \pm 0.1$ & $282 \pm 7$ & $0.22 \pm 0.04$ & $11.2 \pm 0.5$ \\
\hline FC7-21 & $9.93 \pm 0.35^{*}$ & $49 \pm 1$ & $3.1 \pm 0.1$ & $265 \pm 12$ & $0.19 \pm 0.03$ & $18.2 \pm 0.7^{*}$ \\
\hline FC7-18 & $7.86 \pm 0.27^{*}$ & $49 \pm 1$ & $3.5 \pm 0.2$ & $257 \pm 10$ & $0.20 \pm 0.04$ & $16.8 \pm 1.2^{*}$ \\
\hline FC7-8 & $5.52 \pm 0.36^{*}$ & $52 \pm 1$ & $3.8 \pm 0.1$ & $243 \pm 9$ & $0.18 \pm 0.05$ & $17.2 \pm 0.9^{*}$ \\
\hline$F_{1}-2-5$ & $4.77 \pm 0.56$ & $44 \pm 1$ & $2.2 \pm 0.1$ & $254 \pm 8$ & $0.11 \pm 0.01$ & $10.3 \pm 0.6$ \\
\hline FC7-10 & $6.61 \pm 0.33^{*}$ & $53 \pm 1$ & $3.9 \pm 0.2$ & $232 \pm 7$ & $0.16 \pm 0.02$ & $13.4 \pm 0.6^{*}$ \\
\hline$F_{1}-3-4$ & $4.35 \pm 0.25$ & $44 \pm 2$ & $2.6 \pm 0.1$ & $210 \pm 11$ & $0.80 \pm 0.03$ & $11.4 \pm 1.1$ \\
\hline FC7-4 & $8.76 \pm 0.26^{*}$ & $53 \pm 2$ & $4.1 \pm 0.3$ & $204 \pm 13$ & $0.17 \pm 0.02$ & $13.6 \pm 0.9^{*}$ \\
\hline FC7-22 & $3.58 \pm 0.27$ & $46 \pm 1$ & $2.3 \pm 0.3$ & $185 \pm 6$ & $0.12 \pm 0.05$ & $12.1 \pm 1.5$ \\
\hline$F_{1}-3-7$ & $6.52 \pm 0.39^{*}$ & $48 \pm 1$ & $2.9 \pm 0.1$ & $163 \pm 9$ & $0.09 \pm 0.01$ & $14.5 \pm 0.7^{*}$ \\
\hline$F_{1}-3-9$ & $4.03 \pm 0.44$ & $48 \pm 1$ & $2.4 \pm 0.1$ & $193 \pm 8$ & $0.15 \pm 0.01$ & $9.3 \pm 0.6$ \\
\hline FC7-25 & $5.39 \pm 0.38$ & $46 \pm 2$ & $2.8 \pm 0.2$ & $175 \pm 8$ & $0.14 \pm 0.02$ & $14.2 \pm 0.9$ \\
\hline FC7-19 & $3.42 \pm 0.23$ & $50 \pm 3$ & $2.6 \pm 0.2$ & $232 \pm 5$ & $0.17 \pm 0.01$ & $11.6 \pm 0.8$ \\
\hline FC7-9 & $7.83 \pm 0.20^{*}$ & $50 \pm 2$ & $2.9 \pm 0.3$ & $216 \pm 14$ & $0.13 \pm 0.01$ & $15.6 \pm 1.1^{*}$ \\
\hline FC7-17 & $6.25 \pm 0.53^{*}$ & $53 \pm 2$ & $3.2 \pm 0.1$ & $208 \pm 13$ & $0.16 \pm 0.02$ & $11.4 \pm 0.7^{*}$ \\
\hline FC7-7 & $4.88 \pm 0.37$ & $52 \pm 1$ & $2.6 \pm 0.2$ & $295 \pm 16$ & $0.24 \pm 0.03$ & $8.2 \pm 0.6$ \\
\hline$F_{1}-1-3$ & $5.62 \pm 0.31$ & $45 \pm 2$ & $2.2 \pm 0.1$ & $168 \pm 6$ & $0.10 \pm 0.01$ & $8.1 \pm 0.7$ \\
\hline FC7-2 & $7.34 \pm 0.42$ & $50 \pm 1$ & $3.5 \pm 0.2$ & $290 \pm 7$ & $0.20 \pm 0.02$ & $7.2 \pm 0.7$ \\
\hline$F_{1}-3-8$ & $3.86 \pm 0.33$ & $43 \pm 1$ & $1.4 \pm 0.1$ & $184 \pm 6$ & $0.70 \pm 0.05$ & $5.2 \pm 0.6$ \\
\hline$F_{1}-2-4$ & $4.53 \pm 0.45$ & $42 \pm 1$ & $1.8 \pm 0.2$ & $215 \pm 12$ & $0.80 \pm 0.03$ & $7.3 \pm 0.8$ \\
\hline FC7-3 & $2.56 \pm 0.19$ & $47 \pm 2$ & $1.7 \pm 0.1$ & $198 \pm 9$ & $0.14 \pm 0.02$ & $6.5 \pm 0.7$ \\
\hline FC7-1 & $3.54 \pm 0.30$ & $46 \pm 1$ & $2.4 \pm 0.2$ & $178 \pm 8$ & $0.16 \pm 0.01$ & $7.2 \pm 0.6$ \\
\hline$F_{1}-2-1$ & $2.91 \pm 0.34$ & $48 \pm 2$ & $2.5 \pm 0.1$ & $221 \pm 8$ & $0.15 \pm 0.02$ & $8.5 \pm 1.5$ \\
\hline$F_{1}-1-1$ & $4.32 \pm 0.28$ & $48 \pm 1$ & $1.5 \pm 0.2$ & $195 \pm 10$ & $0.12 \pm 0.04$ & $8.4 \pm 0.9$ \\
\hline
\end{tabular}

officinalis, including some hybrid progenies, and since the cultivated rice was a typical $\mathrm{C}_{3}$ plant, for rice breeding, these two $\mathrm{C}_{4}$ genes were potential candidates. These results thus indicated that the high photosynthetic efficiency of Oryza officinalis was transferred to the progeny through distant hybridization (Fig. 2S) and might be an effective $\mathrm{C}_{4}$ photosynthetic pathway.

Genes of PEPC and PPDK were highly expressed in Oryza officinalis, and parent hybrids: To demonstrate photosynthetic pathway expression levels for the related genes of PEPC, rbcS, and PPDK in hybrid progenies of Oryza officinalis, the amplified products of the three genes were sequenced, and primers designed starting from the open reading frame region according to the sequenced qPCR results. Results showed that these gene fragment expression levels were detected in Oryza officinalis, HY-8, and some of the hybrid progenies.

According to the scaffold sequencing, genes of PEPC and PPDK had different sequence characteristics and different primers were designed according to the multiple homologous regions of this scaffold. We detected gene expressions of PEPC and PPDK. The primers PEPC-9.1 and $P E P C$-27.1 were all used to detect the gene of PEPC. However, PEPC-9.1 and PEPC-27.1 were the first primers for the $9^{\text {th }}$ and $27^{\text {th }}$ homologous regions of the PEPC gene, respectively. The amplified products represented the specific sequences of PPDK and PEPC enzyme genes. According to gene expressions detected by primers, PEPC-9.1, PEPC-27.1, and PPDK-11 were significantly higher in Oryza officinalis than that in the Oryza sativa parent, HY-8, and the test hybrid progeny. Similarly, significantly higher hybrid progenies, such as FC7-9, FC7-10, FC7-18, FC7-21, FC7-7, FC7-10, and FC7-18, were detected (Figs. 1, 2). Gene expression detection by primers of PPDK-11 could hardly be detected in Oryza sativa parents but was highly expressed in FC7-7, FC7-2, FC7-17, and $\mathrm{F}_{1}-3-7$ (Fig. 3).

RbcS gene expression, detected by the $r b c S-3.1$ primer, was also expressed in Oryza officinalis, HY-8, and all hybrid progenies. The expression of HY-8 was almost twice that of Oryza officinalis. FC7-10, on the other hand, was almost 3.5 times higher than that of Oryza officinalis, while the expression levels of other hybrid progenies were lower than that of Oryza officinalis (Fig. 4). The results also revealed that the PEPC and PPDK genes of 
E.X. LI et al.

Table 3. 23 pairs of photosynthesis-related specific primer genes in Oryza officinalis.

\begin{tabular}{lll}
\hline Primers & Forward sequence [5'-3'] & Reverse sequence [5'-3'] \\
\hline$P E P C-1$ & CGATGTCGGACTCTGTG & CCTTCACCCTCCTCATA \\
$P E P C-3$ & TGCCAACCACCTCAATAA & TCTCCAACTGAACCTTAC \\
$P E P C-5.1$ & AGGAACGACGCCAAGAGTG & ATGGTCAGGATGAGGGTGT \\
$P E P C-7$ & TTTCATAACACGGGATAC & TCAAGAGTGCTAAGAGAT \\
$P E P C-9$ & CCAACTATGAAGAAACCAA & AAACAACAGTCAACAGAAA \\
$P E P C-12$ & GCTTCCACCTTCCCGTCT & TCCCATCCATCACCTCCT \\
$P E P C-21$ & CGTCCTGGGGAGTGGGCTGTG & GAATGGGATTATGGGTATGTT \\
$P E P C-27$ & GCTGCCTCAGGTATGGGTC & TTTGGATTTCGGGATTGCT \\
$P P D K-1$ & CCCCACTCCCTTCTGGTCAAA & TGGATGGACTTCCTGTGACTA \\
$P P D K-1.2$ & CACAACCCAATCCCTTCCGCA & GTGGTATGACATCTCACGCAG \\
$P P D K-2$ & TTGAAAAGGCAAGAGTGGC & GTGGAGGATTTGGCTGGTA \\
$P P D K-6$ & AATGGCTAAACAGAAAAA & TTGGCTTGCCTGGGAAAC \\
$P P D K-11$ & TCTTTCAAATCCCTGGCA & GTTACTACTTCGTATGGT \\
$r b c S-1$ & TGTCTTGGTTGCCAGTAG & GTGTTCCATAGTATCGCT \\
$r b c S-3$ & AAAGGTCCTCCACTGTCA & TCATCTATCTCTGCTCCA \\
$r b c S-4$ & CCACGGCAGGTTGGACGGGTTG & CAGGGAGGCGGCTTGTCGGAGT \\
$r b c S-6$ & ATAAATAGCCAAAACCAGC & ATCAGTAGCAGAGACAAAG \\
$R u b i s-1$ & TCGCAAACCACCTCCCCCGC & GTTCCATAAGCCAGAAGCAC \\
$R u b i s-2.1$ & CATCTCACTTCACCTTACCG & GCACCTGCTCTCCTTTTCTA \\
$R u b i s-4$ & CATCTCCCGTCTCCCCCTAAA & AAGAAAACCATAATGCTCAAG \\
$R u b i s-5$ & AGACCAAGTTCCACAGCCCAC & GAGAACGCTGCTTTCGGGTGA \\
$R u b i s-10$ & TCCTTGGTAGCCAGTAAAC & CTATGTCACCTTGCCCTG \\
$R u b i s-12.1$ & AATCTCCTGGTCTTGTTGAATA & TTGTGAGCAAAGGGCGACTAAT \\
\hline & &
\end{tabular}

the $\mathrm{C}_{4}$ photosynthetic pathway were highly expressed in Oryza officinalis, which might be responsible for its high photosynthetic efficiency.

Homology analysis of genes of PEPC and PPDK from Oryza officinalis: Based on the transcriptome analysis, less than $40 \%$ of the genome of Oryza officinalis matched to that of the cultivars (Table 2S, supplement), which meant that there were large numbers of new genes in the Oryza officinalis species. We also conducted a homology analysis to understand the sequence characteristics of PEPC and PPDK genes from Oryza officinalis. The amplified products of these PEPC and PPDK genes from Oryza officinalis were sequenced and compared with the reported $\mathrm{C}_{3}$ and $\mathrm{C}_{4}$ crops for homology and cluster analysis. Results showed that the PEPC gene fragment of Oryza officinalis was different from that of $\mathrm{C}_{4}$ crops, such as corn, sugarcane, sorghum, barnyard grass, and $\mathrm{C}_{3}$ crops such as indica rice. There were also many differences in homology and cluster in the CDS and amino acid sequences.

Similarly, the PEPC gene fragment of Oryza officinalis stands on a branch by itself (Fig. 3S, supplement). Similarly, the PPDK gene fragments of Oryza officinalis were different from those of the $\mathrm{C}_{4}$ crops, such as corn and sugarcane, and $\mathrm{C}_{3}$ crops, such as japonica and indica rice. There were also multiple site differences in their CDS and amino acid sequences. Results also showed an independent homologous clustering, as the PPDK gene of Oryza officinalis stands on a branch by itself (Fig. 4S, supplement).

\section{Discussion}

Utilization of high efficiency of photosynthesis and other excellent characteristics of Oryza officinalis: As an ancestor of cultivars with considerable gene resources of excellent traits, wild rice can be considered a gene pool for genetic improvement of cultivars (Hua et al. 2015, Zhang et al. 2016). Oryza officinalis is one of the three wild rice species in China. It contains many excellent traits, such as high photosynthetic efficiency, high biomass accumulation, high carboxylation efficiency, high lightsaturation point, apparent quantum efficiency, and high $P_{\mathrm{N}}$ (Ke et al. 2015). Thus, cross-breeding becomes the main approach for high photosynthetic efficiency breeding of cultivars (photosynthetic physiological characteristics are different between indica $\times$ japonica cross, wild-cultivar cross, and other subspecies) to promote the introduction of the $\mathrm{C}_{4}$ gene and screening for the high photosynthetic efficiency of these plant characteristics (leaf type: color, area, thickness, erect; panicle type: erect and semi-erect; plant height and tiller: appropriate increase of plant height) (Kiran et al. 2013, Wu et al. 2017). To explore and utilize the excellent genes in Oryza officinalis, we constructed an introgression line between indica HY-8 and Oryza officinalis. HY-8 is red rice with good quality and strong disease resistance.

However, Oryza officinalis is a CC genome, quite different from other cultivars, with a low seed-setting rate when distant hybridization occurs. After years of efforts, we obtained the hybrid progeny materials in this study 


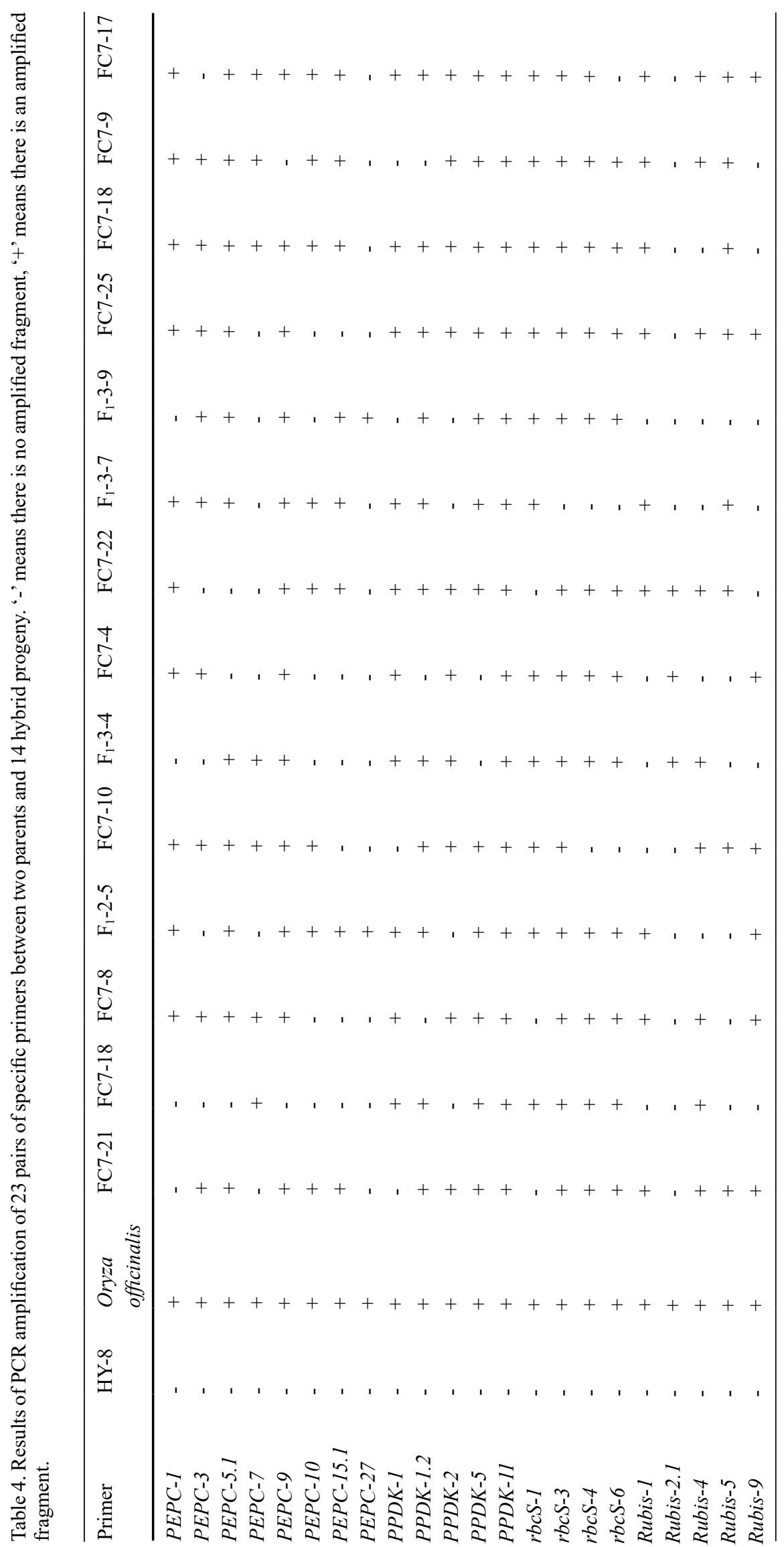




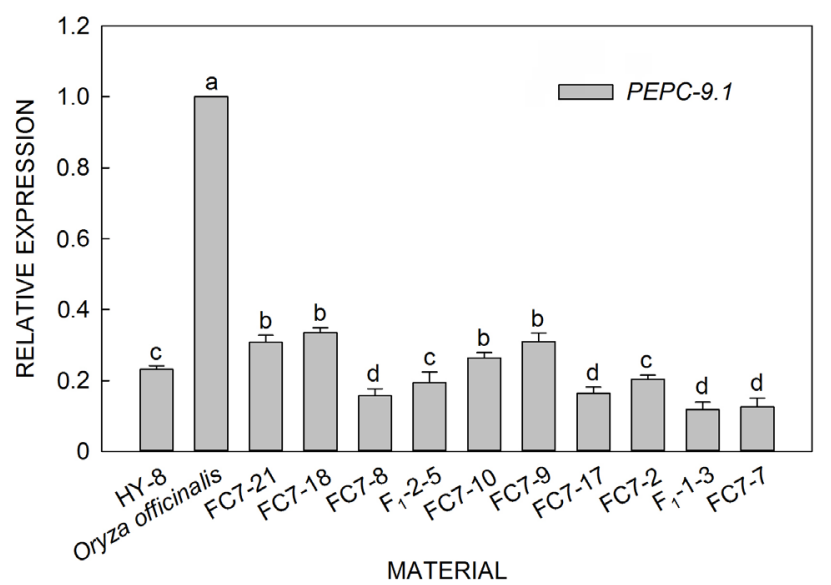

Fig. 1. Expression of photosynthesis-related genes of phosphoenolpyruvate carboxylase, PEPC (detected by primer PEPC-9.1) in Oryza officinalis Wall., HY-8, and some introgression lines. The gene expression of Oryza officinalis as a standard, different lowercase letters indicate significant differences at the 0.05 probability level.

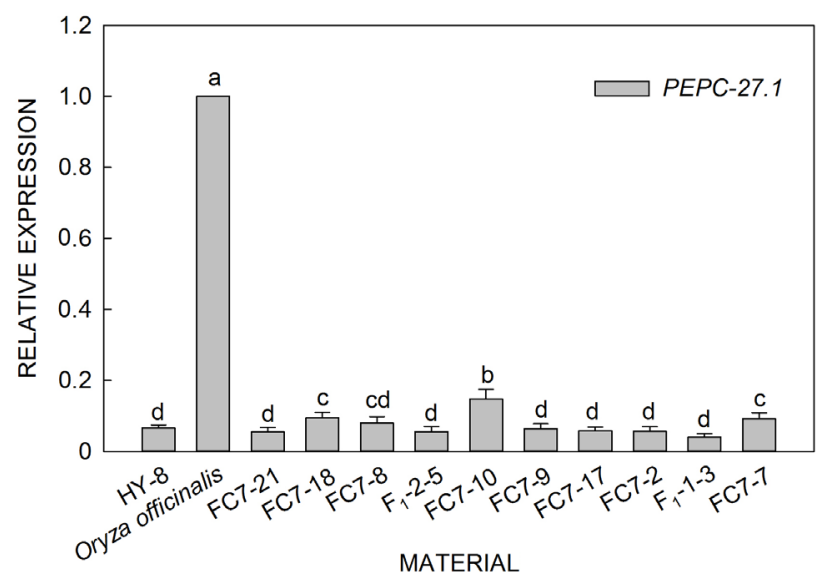

Fig. 2. Expression of photosynthesis-related genes of phosphoenolpyruvate carboxylase, PEPC (detected by primer PEPC-27.1) in Oryza officinalis Wall., HY-8, and some introgression lines. The gene expression of Oryza officinalis as a standard, different lowercase letters indicate significant differences at the 0.05 probability level.

by continuously backcrossing distant hybridization and embryo rescue technology. These germplasm resources are very precious for identifing and screening high photosynthetic efficiency genes.

Field investigations suggest that characters of some hybrid progenies were prominent (Table 1), such as the leaf width, which was up to $3.5 \mathrm{~cm}$, the cultivar, which was generally $1-1.5 \mathrm{~cm}$; large spike, which was up to $40 \mathrm{~cm}$, while the cultivar was generally $15-25 \mathrm{~cm}$; and stem thickness, two times that of the common cultivar in cross-section. These agronomic characteristics reveal the strong growth potential of hybrid progenies, suggesting that Oryza officinalis may contain highly efficient

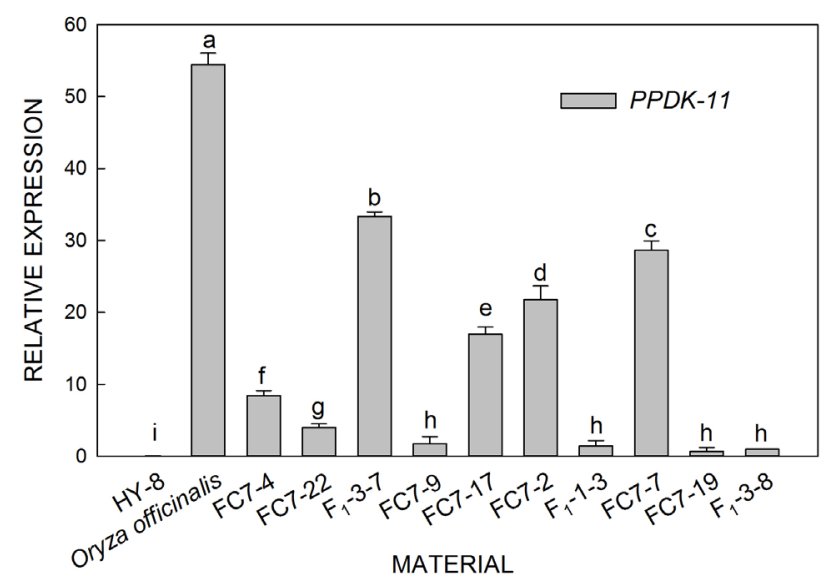

Fig. 3. Expression of photosynthesis-related genes of pyruvate orthophosphate dikinase, PPDK (detected by primer PPDK-11) in Oryza officinalis Wall., HY-8, and some introgression lines. The gene expression of Oryza officinalis as a standard, different lowercase letters indicate significant differences at the 0.05 probability level.

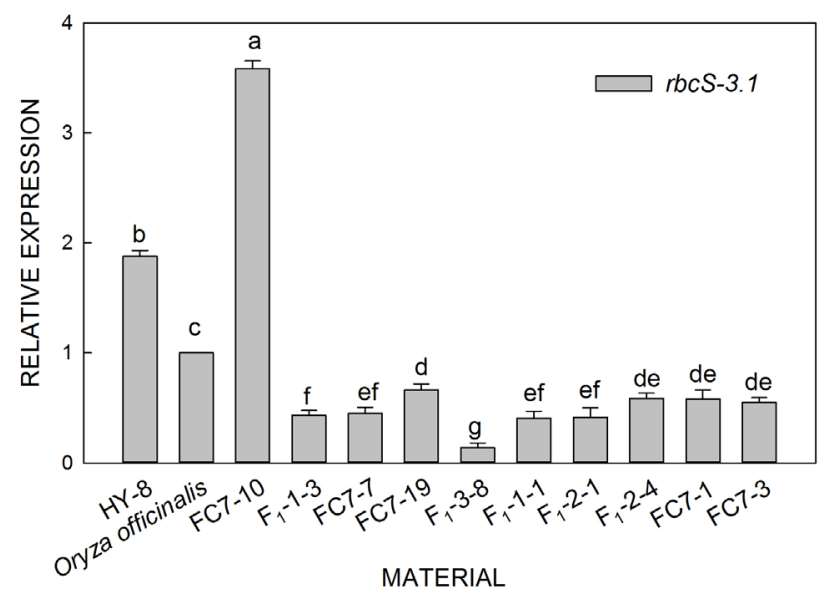

Fig. 4. Expression of photosynthesis-related genes of Rubisco small subunit, rbcS (detected by primer $r b c S-3.1$ ) in Oryza officinalis Wall., HY-8, and some introgression lines. The gene expression of Oryza officinalis as a standard, different lowercase letters indicate significant differences at the 0.05 probability level.

photosynthesis-related gene resources. In this study, we selected eight hybrid progenies with high biomass accumulation and high $P_{\mathrm{N}}$. These materials with a superparent advantage could be used as resource materials for continuous backcross to create hybrid population for breeding for high photosynthetic efficiency.

It is worth exploring for excellent photosynthetic genes, especially $C_{4}$ photosynthetic pathway genes from Oryza officinalis: Genes of PEPC and PPDK identified in the hybrid progeny were genes of $\mathrm{C}_{4}$ photosynthetic pathway enzymes, with a detection rate of more than $70 \%$, and a high expression level in Oryza officinalis. 
Transfer of maize PEPC and PPDK genes to rice plants or overexpression of PEPC gene will improve stability and maintenance of $P_{\mathrm{N}}$, PSII, $\mathrm{F}_{\mathrm{v}} / \mathrm{F}_{\mathrm{m}}$ in cultivars under drought, high light, high temperature, aluminum ion, and other stress. Simultaneously, the cultivars' antioxidant capacities improved significantly by increasing the activities of antioxidant enzymes (SOD, POD, and CAT), thus, facilitating photosynthetic efficiency and yield of cultivars (Ding et al. 2012, 2015). Previous studies have also demonstrated that the high carboxylation efficiency and the concentration of intercellular $\mathrm{CO}_{2}$ were high as well. Combined with the vein anatomical structure of Oryza officinalis, an effective $\mathrm{C}_{4}$ photosynthetic pathway microcirculation in the mesophyll cells of Oryza officinalis could be speculated. Moreover, the photosynthetic pathway-related genes of Oryza officinalis are of great significance as supplements to the genetic basis for improving cultivar photosynthesis.

Compared to the genes related to photosynthetic pathways in $\mathrm{C}_{4}$ plants, Oryza officinalis was more closely related to cultivars. The genes of the same genus showed certain advantages over those of non-Oryza Gramineae. Thus, genes from non-Oryza plants possess potential safety risks due to their distant relationship with Oryza sativa. Simultaneously, there will be issues concerning the expression of regulatory elements in Oryza sativa, affecting functionality. Therefore, it would be a safer and more effective way to identify highly efficient photosynthetic genes, including photosynthetic enzyme genes from Oryza officinalis.

Further studies should determine whether the homologous genes of $\mathrm{C}_{4}$ photosynthetic enzymes PEPC and PPDK from Oryza officinalis are the genes that influence photosynthesis in this crop species. However, based on this study, these two genes showed high expression in the hybrid progenies for both high biomass accumulation and high $P_{\mathrm{N}}$. Nevertheless, due to the low generation of hybrids and the huge genomic differences between wild rice and cultivars, there is no direct correspondence of gene expressions among PEPC, PPDK, and Rubisco small subunit.

In addition to the investigated photosynthetic enzyme genes, many other genes, proteins, or transcription factors also affect photosynthetic efficiencies (Cheng et al. 2016), e.g., SCM/sub (Lin et al. 2012), LPA1 (Wu et al. 2013), srll (Xiang et al. 2012), DELLA proteins related to chloroplast development (Jiang et al. 2012), chloroplast thylakoid Deg2 protease (Sun et al. 2012), and UDP glucose epimerase gene Phdl (Li et al. 2011). Thus, the genetic basis of cultivated rice is relatively single and narrow, while wild rice may contain excellent regulatory elements that regulate photosynthesis. It is also crucial to explore important functional genes and transcriptional regulatory elements from Oryza officinalis, as nearly $60 \%$ of the genome of Oryza officinalis did not match that of cultivars (Table $2 \mathrm{~S}$ ).

In this study, based on the materials of hybrid progenies of Oryza officinalis, specific primers were screened by results of the transcriptome assembly, and photosynthesisrelated genes of the two parents and some hybrid progenies were detected. Four types of photosynthetic genes from Oryza officinalis were then screened; these were the $\mathrm{C}_{4}$ photosynthetic pathway genes of PEPC and PPDK that widely existed in the materials of the hybrid progeny, at a highly expressed level. Subsequently, two homologous genes were isolated, cloned, and edited to verify whether they contain corresponding functions in the $\mathrm{C}_{4}$ photosynthetic pathway. Particularly, the eight hybrid progenies possessed a high photosynthetic rate and large biomass accumulation, thus proposing a promising possibility of being effective for use in high photosynthetic efficiency breeding.

\section{References}

Cheng G., Wang L., Lan H.Y.: Cloning of PEPC-1 from a C4 halophyte Suaeda aralocaspica without Kranz anatomy and its recombinant enzymatic activity in responses to abiotic stresses. - Enzyme Microb. Technol. 83: 57-67, 2016.

Deng H., Zhang L.S., Zhang G.Q. et al.: Evolutionary history of $P E P C$ genes in green plants: Implications for the evolution of CAM in orchids. - Mol. Phylogenet. Evol. 94: 559-564, 2016.

Deng Q.Y., Yuan L.P., Liang F.S. et al.: [Studies on yieldenhancing genes from wild rice and their marker-assisted selection in hybrid rice.] - Hybrid Rice 19: 6-10, 2004. [In Chinese]

Ding Z.S., Huang S.H., Zhou B.Y. et al.: Over-expression of phosphoenolpyruvate carboxylase cDNA from $\mathrm{C}_{4}$ millet (Seteria italica) increase rice photosynthesis and yield under upland condition but not in wetland fields. - Plant Biotechnol. Rep. 7: 155-163, 2013

Ding Z.S., Sun X.F., Huang S.H. et al.: Response of photosynthesis to short-term drought stress in rice seedlings overexpressing $\mathrm{C}_{4}$ phosphoenolpyruvate carboxylase from maize and millet. Photosynthetica 53: 481-488, 2015.

Ding Z.S., Zhou B.Y., Sun X.F. et al.: High light tolerance is enhanced by overexpressed PEPC in rice under drought stress. - Acta Agron. Sin. 38: 285-292, 2012.

Duan M.J., Tang H.Y., Yuan D.Y. et al.: [On key functional photosynthetic factors and ways to breeding for high photosynthetic efficiency in rice.] - Hybrid Rice 23: 1-3, 2008. [In Chinese]

El-Sharkawy M.A.: Prospects of photosynthetic research for increasing agricultural productivity, with emphasis on the tropical $\mathrm{C}_{4}$ Amaranthus and the cassava $\mathrm{C}_{3}-\mathrm{C}_{4}$ crops. Photosynthetica 54: 161-184, 2016.

Gu J.F., Qiu M., Yang J.C.: Enhanced tolerance to drought in transgenic rice plants overexpressing $\mathrm{C}_{4}$ photosynthesis enzymes. - Crop J. 1: 105-114, 2013.

Hua L., Wang D.R., Tan L.B. et al.: LABA1, a domestication gene associated with long, barbed awns in wild rice. - Plant Cell 27: 1875-1888, 2015.

Jiang X.S., Li H.Y., Wang T. et al.: Gibberellin indirectly promotes chloroplast biogenesis as a means to maintain the chloroplast population of expanded cells. - Plant J. 72: 768780, 2012

Ke X., Yin F.Y., Xiao S.Q. et al.: [High photosynthetic efficiency of Oryza officinalis Wall. in Yunnan.] - China Rice 21: 72-76, 2015. [In Chinese]

Kiran T.V., Rao Y.V., Subrahmanyam D. et al.: Variation in leaf photosynthetic characteristics in wild rice species. Photosynthetica 51: 350-358, 2013.

Li C.L., Wang Y.Q., Liu L.C. et al.: A rice plastidial nucleotide sugar epimerase is involved in galactolipid biosynthesis and improves 
photosynthetic efficiency. - PLoS Genet. 7: e1002196, 2011.

Lin L., Zhong S.H., Cui X.F. et al.: Characterization of temperaturesensitive mutants reveals a role for receptor-like kinase SCRAMBLED/STRUBBELIG in coordinating cell proliferation and differentiation during Arabidopsis leaf development. - Plant J. 72: 707-720, 2012.

Murchie E.H., Pinto M., Horton P.: Agriculture and the new challenges for photosynthesis research. - New Phytol. 181: 532-552, 2009.

Sen P., Ghosh S., Sarkar S.N. et al.: Pyramiding of three $\mathrm{C}_{4}$ specific genes towards yield enhancement in rice. - Plant Cell Tiss. Org. 128: 145-160, 2017.

Shen W.J., Chen G.X., Xu J.G. et al.: Overexpression of maize phosphoenolpyruvate carboxylase improves drought tolerance in rice by stabilization the function and structure of thylakoid membrane. - Photosynthetica 53: 436-446, 2015.

Shen W.J., Ye L.H., Ma J. et al.: The existence of $\mathrm{C}_{4}$-bundlesheath-like photosynthesis in the mid-vein of $\mathrm{C}_{3}$ rice. Rice 9: 20, 2016.

Sun R.H., Fan H.T., Gao F. et al.: Crystal structure of Arabidopsis Deg2 protein reveals an internal PDZ ligand locking the hexameric resting state. - J. Biol. Chem. 287: 37564-37569, 2012.

Suzuki Y., Ohkubo M., Hatakeyama H. et al.: Increased Rubisco content in transgenic rice transformed with the 'sense' $r b c S$ gene. - Plant Cell Physiol. 48: 626-637, 2007.

von Caemmerer S., Quick W.P., Furbank R.T.: The development of $\mathrm{C}_{4}$ rice: current progress and future challenges. - Science 336: 1671-1672, 2012.

Wang P., Vlad D., Langdale J.A.: Finding the genes to build $\mathrm{C}_{4}$ rice. - Curr. Opin. Plant Biol. 31: 44-50, 2016.

Wang Z.M., Li H.X., Liu X.F. et al.: Reduction of pyruvate orthophosphate dikinase activity is associated with high temperature-induced chalkiness in rice grains. - Plant Physiol. Bioch. 89: 76-84, 2015.

Wu J.T., Qi Y.W., Hu G.L. et al.: Genetic architecture of flag leaf length and width in rice (Oryza sativa L.) revealed by association mapping. - Genes Genom. 39: 341-352, 2017.

Wu X.R., Tang D., Li M. et al.: Loose plant architecture 1, an INDETERMINATE DOMAIN protein involved in shoot gravitropism, regulates plant architecture in rice. - Plant Physiol. 161: 317-329, 2013.

Xiang J.J., Zhang G.H., Qian Q. et al.: SEMI-ROLLED LEAF1 encodes a putative glycosylphosphatidylinositol-anchored protein and modulates rice leaf rolling by regulating the formation of bulliform cells. - Plant Physiol. 159: 1488-1500, 2012.

Yang K.S., He H.H., Chen X.R.: [Excavation and utilization of beneficial genes in wild rice and research progress.] - Seed. 24: 92-95, 2005. [In Chinese]

Yang Q.Y., Qiao J.F.: [The application of Li-6400 portable photosynthesis system in rice and analysis of common problems.] - Res. Explor. Lab. 28: 52-55, 2009. [In Chinese]

Ye Z.P., Yu Q.: [Comparison of new and several classical models of photosynthesis in response to irradiance.] - Chin. J. Plant Ecol. 32: 1356-1361, 2008. [In Chinese]

Zhang F., Chi W., Wang Q. et al.: Molecular cloning of $\mathrm{C}_{4}$-specific $P p c$ gene of sorghum and its high level expression in transgenic rice. - Chin. Sci. Bull. 48: 1835-1840, 2003.

Zhang F.T., Xu T., Mao L.Y.: Genome-wide analysis of Dongxiang wild rice (Oryza rufipogon Griff.) to investigate lost/acquired genes during rice domestication. - BMC Plant Biol. 16: 103, 2016.

Zhang Y.W., Zhao X.G., Guan ZH.B. et al.: [The review on screening crop germplasm resources with high photosynthetic efficiency.] - Chin. Agr. Sci. Bull. 35: 1-11, 2019. [In Chinese]

(C) The authors. This is an open access article distributed under the terms of the Creative Commons BY-NC-ND Licence. 